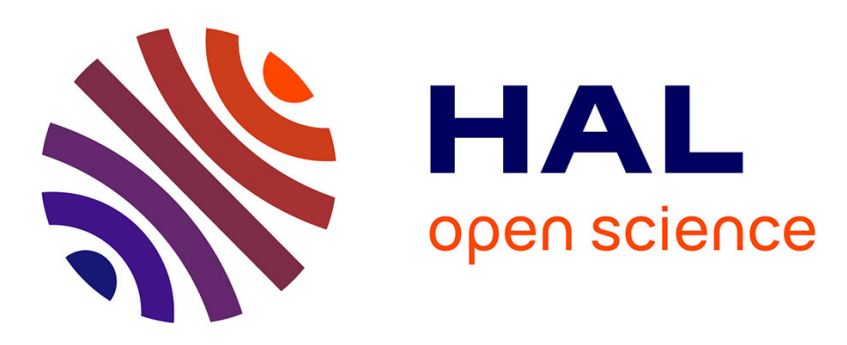

\title{
Should licking behavior be considered in the bioavailability evaluation of transdermal products?
}

Pierre-Louis Toutain, Sanja Modric, Alain Bousquet-mélou, Juan M Sallovitz, Carlos Lanusse

\section{- To cite this version:}

Pierre-Louis Toutain, Sanja Modric, Alain Bousquet-mélou, Juan M Sallovitz, Carlos Lanusse. Should licking behavior be considered in the bioavailability evaluation of transdermal products?. Journal of Veterinary Pharmacology and Therapeutics, 2012, 35, pp.39-43. 10.1111/j.1365-2885.2012.01380.x . hal-01136992

\section{HAL Id: hal-01136992 \\ https://hal.science/hal-01136992}

Submitted on 14 Nov 2015

HAL is a multi-disciplinary open access archive for the deposit and dissemination of scientific research documents, whether they are published or not. The documents may come from teaching and research institutions in France or abroad, or from public or private research centers.
L'archive ouverte pluridisciplinaire HAL, est destinée au dépôt et à la diffusion de documents scientifiques de niveau recherche, publiés ou non, émanant des établissements d'enseignement et de recherche français ou étrangers, des laboratoires publics ou privés. 


\section{Should licking behavior be considered in the bioavailability evaluation of transdermal products?}

\author{
P.-L. TOUTAIN ${ }^{*} \dagger$ \\ S. MODRIC \\ A. BOUSQUET-MÉLOU*, $\dagger$ \\ J. M. SALLOVITZ ${ }^{\S} \&$ \\ C. LANUSSE ${ }^{\S}$
}

"INRA, UMR1331, Toxalim, Toulouse, France; ‘Université de Toulouse, INPT, ENVT, EIP, UPS, Toulouse, France; ${ }^{\ddagger} U . S$. Food and Drug Administration - Center for Veterinary Medicine, Rockeville, MD, USA;

${ }^{\S}$ Laboratorio de Farmacología,

Departamento de Fisiopatología, Facultad de Ciencias Veterinarias, Universidad Nacional del Centro de la Provincia de Buenos Aires, Campus Universitario (UNCPBA), Tandil, Argentina
Toutain, P.-L., Modric, S., Bousquet-Mélou, A., Sallovitz, J. M., Lanusse, C. Should licking behavior be considered in the bioavailability evaluation of transdermal products? J. vet. Pharmacol. Therap. 35 (Suppl. 1), 39-43.

Antiparasitic drugs, and especially macrocyclic lactones (MLs), are often formulated as pour-on products because of their ease of administration, convenience, and reduction of stress in treated animals. However, because of self- and allo-grooming, much of a drug administered transdermally may be systemically absorbed via the oral route, creating highly variable pharmacokinetic and pharmacodynamic response in treated (and untreated) animals. Testing bioequivalence (BE) of pour-on drugs in cattle under laboratory conditions (with restricted licking) ignores a major factor of drug disposition of these drugs and thus fails to predict therapeutic equivalence in the target population under clinical conditions of use. Therefore, the interanimal and intra-animal variability associated with licking behavior should be considered as a biological fact, rather than a noise that needs to be reduced or eliminated. As a result, it is recommended that the BE testing for pour-on products in cattle be conducted by evaluating both the mean and distribution of bioavailability parameters between the reference and test products when animals are not prevented from allo- and self-licking.

(Paper received 23 December 2011; accepted for publication 30 December 2011)

Pierre-Louis Toutain, Ecole Nationale Veterinaire de Toulouse, 23 chemin des Capelles, BP 87614,F-31076 Toulouse,France.E-mail: pl.toutain@envt.fr

\section{INTRODUCTION}

Transdermal $^{1}$ route of administration is favored by clinicians and animal handlers for its inherent ease of use and the ability to minimize animal handling and stress. The most commonly used products in food animal practice are various antiparasitics, especially when formulated as pour-on products. Macrocyclic lactones (MLs) in particular, such as ivermectin (IVM), doramectin (DOR), eprinomectin (EPR), and moxidectin (MOX), are administered transdermally to treat different endoand ectoparasite infections in cattle. Pour-on formulations are

\footnotetext{
${ }^{1}$ Literature on the use of pour-on drugs in animals often refers to this route as topical, and the terms topical and transdermal are sometimes used interchangeably. The target of drug action for topical products is the skin, and the systemic absorption for topical products is not desirable (Desai, 2007). On the other hand, the goal of a transdermal application is predictable absorption of the drug through the skin into the general circulation. As the pour-on products described in this article were designed to deliver the drug systemically, the term transdermal is used throughout this manuscript when describing the route of administration of pour-on drugs.
}

considered transdermal formulations by international regulatory bodies for the approval of new veterinary drugs. However, a large fraction of the MLs poured onto the backs of cattle displaying normal allo- and self-grooming activities do not gain access to the systemic circulation via transdermal absorption, but rather by the oral route as a consequence of licking behavior. As self- and allo-grooming are governed by various social, nutritional, physiological, pathological, environmental, and managerial factors, they make the systemic availability of the pour-on drug formulation highly variable.

This previously unaccounted for licking behavior of cattle creates highly variable drug pharmacokinetics and pharmacodynamics in treated animals that may impact the design of clinical and bioequivalence (BE) trials for pour-on drugs. Concerns with the effect of licking on drug fate in the body were recently discussed at the AAVPT/EAVPT/ECVCP Workshop of BE Issues in Veterinary Medicine (Potomac, MD, June 2010). The present white paper is focused on further addressing the issues of demonstrating product BE for highly variable pouron formulations. 


\section{INTERANIMAL VARIABILITY IN THE DISPOSITION OF POUR-ON FORMULATIONS}

Pour-on formulations are associated with a very large interanimal variability in drug exposure, challenging the demonstration of blood-level BE between two pour-on products. In an experiment comparing the plasma pharmacokinetics of DOR and IVM after transdermal dose $(500 \mu \mathrm{g} / \mathrm{kg})$ involving two parallel groups of 12 young beef cattle, it was shown that the range of AUC values calculated for IVM and DOR was very large, with extreme values extending from 1 to 3.6 for IVM and from 1 to 2.2 for DOR (coefficient of variation [CV] of $37.2 \%$ and $24.8 \%$ for IVM and DOR, respectively) (Gayrard et al., 1999). A highly variable exposure was also reported for MOX $(500 \mu \mathrm{g} / \mathrm{kg})$ in calves (Sallovitz et al., 2002) with an estimated CV for the exposure of $36 \%$ in 8 Aberdeen angus calves and $34 \%$ in 8 Holstein calves. For a pour-on formulation of EPR in 5 dairy cattle, the corresponding CV was 32\% (Alvinerie et al., 1999). Research by Sallovitz et al. (2005) demonstrated that the variation range for DOR plasma AUCs reached a value 1.32 in Holstein male calves. However, more recent work showed that the variation range in MOX plasma AUCs when administered as a pour-on may reach a value of up to 7.32 in treated Holstein dairy cows (Imperiale et al., 2009). In licking-restricted animals ( 2 and 5 days of post-treatment restriction to avoid selfand allo-licking), the variation range was smaller, but the interindividual variability remained high with the variation range of 3.77 ( $\mathrm{CV}=25.6 \%$ up to 2 days post-treatment) for DOR and 2.64 ( $\mathrm{CV}=32.5 \%$ up to 5 days post-treatment) for MOX.

\section{WITHIN-SUBJECT VARIABILITY IN THE DISPOSITION OF POUR-ON FORMULATIONS}

In the late nineties, the question of optimal design of BE trials for pour-on formulations was under investigation at Toulouse. At that time, it was considered that a classical crossover study design for endectocides was not ideal owing to a very long terminal half-life necessitating a long washout period (where 10 times the terminal half-life of DOR pour-on is about 100 days, and for an IVM pour-on formulation, it is over 50 days). Therefore, a parallel study design was more appropriate than a crossover study design for testing BE of pour-on formulations. However, in any study employing a parallel design, the residual error term, which has to be considered to compute confidence intervals, is very large (vide supra), and a parallel design is typically assumed to be less powerful than a crossover design, which takes into account the intra-animal variability to compute confidence intervals. To overcome this downside of a parallel study design while benefitting from its advantage for testing long-acting drugs (and being able to keep the intraanimal variability as an error term for the BE data analysis), Laffont et al. (2001, 2003) hypothesized that using pairs of cloned twin cattle could be an elegant solution. At that time, it was assumed that cloned pairs of cattle functioned as replicates of the same animal. Thus, it was hypothesized that the use of the cloned animals could replicate a within-subject comparison, thereby minimizing erratic absorption of MLs. This hypothesis was tested by measuring the repeatability and reproducibility of IVM kinetics in six pairs of monozygotic twin cattle as cloned by Ozil et al. (1982). After birth, the cloned twin cattle were maintained in exactly the same conditions for more than 3 years to maintain comparable conditions throughout the duration of the study. When cattle were 16 months old $(403 \pm 16 \mathrm{~kg} \cdot \mathrm{BW})$, a classical BE trial (but comparing the same IVM formulation administered at $500 \mu \mathrm{g} / \mathrm{kg}$ ) was performed using a crossover study design and a washout period of 3 months. About 4 months later, each subject was administered an IV dose of IVM $(200 \mu \mathrm{g} / \mathrm{kg})$ when they were $501 \pm 25 \mathrm{~kg} \cdot \mathrm{BW}$. Based upon the IV administration, an excellent intrapair reproducibility of the IVM disposition was observed $(\mathrm{CV}=5 \%)$, thereby supporting the authors' first assumption that cloned twin cattle behaved as replicates of the same individual. However, the use of cloned twin animals did not reduce the pharmacokinetics (PK) variability following the pour-on administration, and a very large interpair and intrapair exposure variability was observed $(\mathrm{CV}=41 \%$ vs. $\mathrm{CV}=55 \%$, for intraindividual and interindividual variability, respectively). This variability rendered it impossible to demonstrate the $\mathrm{BE}$ of the formulation with itself. In addition, the absolute bioavailability of IVM in the second period of the BE trial ranged from $16.6 \%$ to $57.7 \%$ (Laffont et al., 2000, 2003), indicating that the factors responsible for the large variability in bioavailability after a pour-on administration of IVM were unlikely of genetic origin. During these various trials, both plasma and fecal samples were collected and the fecal clearances of IVM after pour-on were observed to be much greater than the corresponding plasma clearance, which is theoretically impossible and was not the case after the IV administration of IVM. To explain this phenomenon, a possible oral ingestion of IVM administered as a pour-on in cattle that were allowed to lick was suspected.

Licking is a form of grooming behavior in cattle, which can lick another conspecific animal (mutual/social or allo-grooming within a species) or themselves (self-licking). Cattle can lick most areas of their body, and mutual licking (social grooming) has a social function, helping to establish and maintain social bonds within the herd. According to a study by Sato et al., 1991, heifers and steers respectively had on average 15.0 and 15.2 social licking interactions per hour (under various housing and environmental conditions), which lasted for 37.8 and $41.0 \mathrm{sec}$.

The impact of this social behavior on the disposition of ML products administered transdermally was further investigated in multiple studies summarized in Table 1 below. Those studies clearly demonstrated that the mechanism of IVM absorption differed between licking and nonlicking animals, and that a large fraction of the IVM poured onto the skin of cattle displaying normal grooming activities do not gain access to systemic circulation by transdermal absorption, but by the oral route (as a consequence of the licking behavior). The Lanusse group in 
Table 1. Summary of studies investigating the impact of licking on disposition of marcrocyclic lactones in cattle

\begin{tabular}{|c|c|c|c|}
\hline Reference & Pour-on drug & Study animals & Summary of findings \\
\hline Laffont et al., 2001 & IVM & 6 pairs of twin cattle & $\begin{array}{lc}\text { Parameter } & \text { Lickers } \\
\mathrm{F}(\%) & 33( \pm 18.5) \\
\mathrm{T}_{1 / 2 \text { elim. }}(\mathrm{h}) & 154( \pm 7.4)\end{array}$ \\
\hline Laffont et al., 2003 & IVM & 6 pairs of twin cattle & $\begin{array}{l}58 \text { to } 87 \% \text { of IVM dose is ingested, only } 10 \% \\
\text { absorbed percutaneously; } \\
\text { Approximately } 72 \% \text { of the ingested IVM transited } \\
\text { directly into feces of licking animals, with a } 7 \text {-fold } \\
\text { higher fecal excretion of IVM than in nonlickers. }\end{array}$ \\
\hline Sallovitz et al., 2003 & MOX & $\begin{array}{l}16 \text { male Holstein calves } \\
\text { under clinical use conditions }\end{array}$ & $\begin{array}{l}\text { Highest MOX bioavailability was observed in the } \\
\text { skin layers at the site of administration and in the } \\
\text { fat tissue; } \\
\text { Intestinal fluid AUCs were } 2.7-9.1 \text {-fold higher than } \\
\text { those in respective mucosal tissues; } \\
\text { Large differences in bioavailability in skin from } \\
\text { different anatomical regions (backline>rib } \\
\text { cage }>\text { thigh }>\text { face) }\end{array}$ \\
\hline $\begin{array}{l}\text { Bousquet-Mélou } \\
\text { et al., } 2004\end{array}$ & $\begin{array}{l}\text { Mix of IVM + } \\
\text { DOR + MOX }\end{array}$ & $\begin{array}{l}4 \text { pairs of twin cattle } \\
2 \text { IVM } \\
2 \text { DOR } \\
2 \text { MOX } \\
2 \text { untreated }\end{array}$ & $\begin{array}{l}\text { Demonstrated licking-driven transfer of IVM, DOR, } \\
\text { and MOX from treated to untreated animals } \\
1.3-16.1 \% \text { of the IVM pour-on dose was ingested } \\
\text { by } 5 / 6 \text { IVM-untreated cows; } \\
1.3-21.3 \% \text { of the DOR pour-on dose was ingested } \\
\text { by } 5 / 6 \text { DOR-untreated cows; } \\
2.4-10.6 \% \text { of the MOX pour-on dose was ingested } \\
\text { by } 6 \text { MOX-untreated cows. }\end{array}$ \\
\hline Sallovitz et al., 2005 & DOR & $\begin{array}{l}16 \text { Holstein calves (licking } \\
\text { vs. nonlicking) under } \\
\text { clinical use conditions }\end{array}$ & $\begin{array}{l}\text { DOR concentrations in the abomasal fluid were } \\
38 \text {-fold higher in licking than in nonlicking calves } \\
\text { (10 days post-treatment); } \\
\text { Presence of double peaks was more evident in the } \\
\text { 2-day licking-restricted group (with second peak } \\
\text { observed after licking was allowed); } \\
78 \text { to } 82 \% \text { of total drug recovered in bloodstream } \\
\text { was due to oral ingestion }\end{array}$ \\
\hline $\begin{array}{l}\text { Imperiale et al., } \\
2009\end{array}$ & MOX & $\begin{array}{l}10 \text { lactating Holstein } \\
\text { cows (licking vs. } \\
\text { nonlicking) }\end{array}$ & $\begin{array}{l}\text { MOX results in markedly higher plasma and milk } \\
\text { concentrations when dairy cows are allowed to } \\
\text { lick (AUC ranged from } 2.09 \pm 0.80 \text { in nonlicking } \\
\text { vs. } 25.7 \pm 17.6 \mathrm{ng} \cdot \mathrm{d} / \mathrm{mL} \text { in free-licking cows); } \\
\text { At the end of the restriction period, self- and } \\
\text { allo-licking permitted a dramatic increase in MOX } \\
\text { plasma concentrations, where the partial AUC } \\
\text { values of the post-restriction period accounted for } \\
87.6 \% \text { of the total AUC; } \\
\text { Two Cmax values were observed in the nonlicking } \\
\text { group (the first one during the nonlicking period, } \\
\text { and the second one during the licking period } \\
\text { (3.93 } \pm 1.8 \text { ng/mL), with the Cmax } 1 / \text { Cmax } 2 \\
\text { ratio of } 6.27 \pm 4.52 \text {; } \\
\text { MOX milk profiles were similar to those in plasma, } \\
\text { but a delayed Cmax was observed in both groups }\end{array}$ \\
\hline $\begin{array}{l}\text { Bousquet-Mélou } \\
\text { et al., } 2011\end{array}$ & IVM & $\begin{array}{l}\text { Calves experimentally } \\
\text { infected with } \\
\text { Ostertagia ostertagi } \\
\text { and Cooperia oncophora }\end{array}$ & $\begin{array}{l}\text { Licking-driven transfer of IVM from treated to } \\
\text { untreated animals resulted in anthelmintic } \\
\text { effectiveness in untreated animals of up to } 100 \% \text {; } \\
\text { IVM transfer did not significantly impact the } \\
\text { efficacy of IVM in the treated heifers (when oral } \\
\text { ingestion by self-licking was not restricted) }\end{array}$ \\
\hline
\end{tabular}

DOR, doramectin; IVM, ivermectin; MOX, moxidectin.

Argentina further confirmed the impact of licking as a mechanism of ML disposition and demonstrated its relevance under clinical conditions of use (Sallovitz et al., 2003, 2005).
Another aspect of dermal absorption that should be kept in mind is the intrasubject variability observed when in vitro assays were used to determine percutaneous absorption (flux) of

Published 2012. This article is a U.S. Government work and is in the public domain in the USA. 
DOR and MOX through the limited skin layer (stratum corneum) (Sallovitz et al., 2011; Henning et al., 2009). Even though the skin sections used for in vitro experiments were obtained from the same animal and anatomical region (withers), flux values showed a large variability (84\% for MOX and $81 \%$ for DOR) (Sallovitz et al., 2011). Hence, absorptive behavior of the skin in any individual animal may present additional interindividual variation depending on the anatomical region and the physiological status of the skin (particularly when considering weather conditions) (Pitman et al., 1983). The interindividual variability will contribute to the overall variability by adding to that determined by licking behavior, as illustrated in vivo by Imperiale et al. (2009) during a 5-day licking-restriction period. Further work on an in vitro skin absorption model useful to predict in vivo drug permeation is currently being performed by Sallovitz and coworkers in Argentina.

\section{THE EFFECT OF FORMULATION ON DISPOSITION OF POUR-ON DRUGS}

Bioequivalence studies, by definition, evaluate the formulation effect, while the active pharmaceutical ingredient remains the same. When dealing with drugs that are administered as pourons, a certain percentage of the drug will be ingested, as demonstrated in the studies summarized above. Because of the potential differences in quantities and characteristics of excipients between the two formulations tested, it is quite possible that the effect of licking will vary between the two formulations. For example, if one of the excipients in one formulation is more palatable to cattle than the excipients in the other one, it will result in a higher percentage of the drug being licked vs. percutaneously absorbed, changing the pharmacokinetic patterns across the two groups. If the animals are restricted from licking, then this formulation effect would not be accounted for in a traditional BE study. As a result, such two drugs would be considered bioequivalent, although it is likely that there would be marked differences in their disposition (and potentially, their clinical effect) under their normal conditions of use. Therefore, when considering use of a blood-level BE study for assessing pharmacologic similarity between two formulations administered as pour-ons, it is critical to consider the possible impact of their excipients on drug disposition and palatability, as well as the role of oral absorption.

Finally, because of the large variability in PK response observed in animals when drugs are administered as pour-ons (which is, at least partly, due to licking), it is possible that the effect of licking (oral absorption) will obscure the differences in transdermal bioavailability. As a result, any studies that compare bioavailability of pour-on formulations should address the role of oral vs. transdermal absorption on drug disposition. Only if the bioavailability of each of the two routes is equivalent between the two formulations, the two products can be considered truly pharmacologically bioequivalent.
CONSIDERATIONS FOR THE BE TESTING OF POUR-ON FORMULATIONS

Currently, successful BE trials are performed for pour-on products, although the data suggest that, unless the animals are prevented from licking, the interindividual and intraindividual variability associated with these formulations could make such a demonstration difficult. In the past, the veterinary scientific community was not aware of the impact of licking on drug behavior in the body, and this issue was not considered in the design of BE studies. If licking was prevented, the method and rationale for this stipulation were neither reported nor justified.

Future studies for the evaluation of pour-on drugs in cattle should include elimination of any major bias in the experimental design. Such bias would include the presence of factors (e.g., licking restriction) that may cause the results to deviate systematically from those that would have been observed under clinical use conditions. In addition, the interanimal and intraanimal variability associated with licking behavior should be considered as a biological fact, not as a noise that should be reduced or eliminated in an experimental setting. Testing drug $\mathrm{BE}$ under laboratory conditions with restricted licking ignores a major factor of drug disposition of these drugs in the target population under clinical use conditions. Currently, the BE trials are conducted in accordance with Good Laboratory Practice (GLP) regulations for both the FDA and EMA requirements. However, in the last version of the future EMA guidelines (November 2011), it states: 'Bioequivalence studies should be conducted under GLP and/or Good Clinical Practice (GCP), as appropriate'. In the United States, any type of BE studies (i.e., blood level, pharmacologic endpoint, and clinical endpoint studies) should be conducted in accordance with GLP regulations (21 CFR Part 58), as described in the FDA-CVM Guidance for Industry \# 35: Bioequivalence Guidance. Regardless of the standard of conduct followed, the data on the impact of licking suggest that the cattle's natural social behaviors be considered in the design of these studies by allowing the animals to lick (both themselves and other animals).

If blood-level BE trials are performed under field conditions (i.e., without preventing self- and allo-licking), variability (inter and/or intra) could be very large, in many cases preventing a demonstration of BE. However, in the case of pour-on formulations, this variability is not a noise that needs to be eliminated (as is often the case in BE studies), but a valuable biological variable that should be incorporated in the study design. In the context of a BE pour-on trial, two formulations giving the same average exposure (AUC) but being different in the statistical distribution of the PK parameters could be considered as not bioequivalent. Therefore, several approaches have been proposed for the evaluation of BE trials of highly variable drugs, including expansion of the $\mathrm{BE}$ limits based on fixed sample size and widening of $\mathrm{BE}$ limits based on the within variability of the reference formulation (see Haidar et al.(2008) for details). In addition, a separate white paper (by Claxton et al., 2012) in this series of articles for demonstrating BE of veterinary drugs further 
explores the statistical approaches for establishing product BE for highly variable veterinary drugs.

\section{CONCLUSION}

There is clear evidence that the natural grooming behavior of cattle influences the kinetic disposition of all transdermally administered MLs. As self- and allo-grooming are governed by various social, nutritional, physiological, pathological, environmental, and managerial factors, the systemic availability of the pour-on drug formulations could be highly variable. Therefore, BE testing should take the effect of licking into consideration for demonstrating the interchangeability of the pour-on formulations by evaluating both the mean and distribution of bioavailability parameters between the reference and test products. In addition, because of the potential impact of different excipients on drug palatability (and therefore, the likelihood of licking), as well as on drug absorption, one should also consider the specific role and impact that excipients have on oral (via licking) vs. transdermal route of absorption on drug disposition.

\section{CONFLICTS OF INTEREST}

The authors declare no conflicts of interest.

\section{REFERENCES}

Alvinerie, M., Sutra, J.F., Galtier, P. \& Mage, C. (1999) Pharmacokinetics of eprinomectin in plasma and milk following topical administration to lactating dairy cattle. Research in Veterinary Science, 67, 229-232.

Bousquet-Mélou, A., Mercadier, S., Alvinerie, M. \& Toutain, P.L. (2004) Endectocide exchanges between grazing cattle after pour-on administration of doramectin, ivermectin and moxidectin. International Journal for Parasitology, 34, 1299-1307.

Bousquet-Mélou, A., Jacquiet, P., Hoste, H., Clément, J., Bergeaud, J.P., Alvinerie, M. \& Toutain, P.L. (2011) Licking behaviour induces partial anthelmintic efficacy of ivermectin pour-on formulation in untreated cattle. International Journal for Parasitology, 41, 563-569.

Claxton, R., Cook, J., Endrenyi, L., Lucas, A., Martinez, M.N. \& Sutton, S.C. (2012) Estimating product bioequivalence for highly variable drugs. Journal of Veterinary Pharmacology and Therapeutics, 35 (Suppl. 1), $11-16$.

Desai, A. (2007). Topical and transdermal delivery systems. In Gibaldi's Drug Delivery Systems in Pharmaceutical Care. Eds Desai, A. \& Lee, M., pp. 43-58. American Society of Health-System Pharmacists, Inc., Bethesda, MD.

US Food and Drug Administration Animal \& Veterinary Guidances Guidance for Industry \# 35: Bioequivalence Guidance. http://www.
fda.gov/downloads/AnimalVeterinary/GuidanceComplianceEnforcement/ GuidanceforIndustry/ucm052363.pdf

Gayrard, V., Alvinerie, M. \& Toutain, P.L. (1999) Comparison of pharmacokinetic profiles of doramectin and ivermectin pour-on formulations in cattle. Veterinary Parasitology, 81, 47-55.

Haidar, S.H., Davit, B., Chen, M.L., Conner, D., Lee, L., Li, Q.H., Lionberger, R., Makhlouf, F., Patel, D., Schuirmann, D.J. \& Yu, L.X. (2008) Bioequivalence approaches for highly variable drugs and drug products. Pharmaceutical Research, 25, 237-241.

Henning, A., Schaefer, U. \& Nuemann, D. (2009) Potential pitfalls in skin permeation experiments: influence of experimental factors and subsequent data evaluation. European Journal of Pharmaceutics and Biopharmaceutics, 72, 324-331.

Imperiale, F., Sallovitz, J., Farias, C., Lifschitz, A. \& Lanusse, C. (2009) Licking induced changes to the pattern of moxidectin milk elimination after topical treatment in dairy cows. Journal of Veterinary Pharmacology and Therapeutics, 32, 534-540.

Laffont, C., Bousquet-Melou, A., Alvinerie, M. \& Toutain, P.L. (2000) Bioavailability of ivermectin pour-on formulation in cattle. In: 8th International Congress of the European Association for Veterinary Pharmacology and Toxicology (EAVPT), Jerusalem, Israel.

Laffont, C.M., Alvinerie, M., Bousquet-Mélou, A. \& Toutain, P.L. (2001) Licking behaviour and environmental contamination arising from pour-on ivermectin for cattle. International Journal of Parasitology, 31, 1687-1692.

Laffont, C.M., Bousquet-Mélou, A., Bralet, D., Alvinerie, M., Fink Gremmels, J. \& Toutain, P.L. (2003) A pharmacokinetic model to document the actual disposition of topical ivermectin in cattle. Veterinary Research, 34, 445-460.

Ozil, J.P., Heyman, Y. \& Renard, J.P. (1982) Production of monozygotic twins by micromanipulation and cervical transfer in the cow. Veterinary Research, 110, 126-127.

Pitman, I., Rostas, S. \& Leanne, M. (1983) Effects of breed, season, temperature, and solvents on the permeability of frozen and reconstituted skin to levamisole. Journal of Pharmaceutical Sciences, 72, 218-221.

Sallovitz, J., Lifschitz, A., Imperiale, F., Pis, A., Virkel, G. \& Lanusse, C. (2002) Breed differences on the plasma availability of moxidectin administered pour-on to calves. Veterinary Journal, 164, 47-53.

Sallovitz, J., Lifschitz, A., Virkel, G. \& Lanusse, C. (2003) A detailed assessment of the pattern of moxidectin tissue distribution after pouron treatment in calves. Journal of Veterinary Pharmacology and Therapeutics, 26, 397-404.

Sallovitz, J.M., Lifschitz, A., Imperiale, F., Virkel, G., Larghi, J. \& Lanusse, C. (2005) Doramectin concentration profiles in the gastrointestinal tract of topically-treated calves: influence of animal licking restriction. Veterinary Parasitology, 133, 61-70.

Sallovitz, J.M., Nejamkin, P., Lifschitz, A.L., Virkel, G.L., Imperiale, F.A. \& Lanusse, C.E. (2011) Comparative in vitro characterization of moxidectin and doramectin percutaneous absorption through bovine skin. Journal of Veterinary Pharmacology and Therapeutics, doi: 10.1111/ j.1365-2885.2011.01302.x.

Sato, S., Sako, S. \& Maeda, A. (1991) Social licking patterns in cattle (Bos-Taurus) - influence of environmental and social-factors. Applied Animal Behaviour Science, 32, 3-12. 